\title{
Aging after Noise Exposure: Acceleration of Cochlear Synaptopathy in "Recovered" Ears
}

\author{
Katharine A. Fernandez, ${ }^{1,2}$ Penelope W.C. Jeffers, ${ }^{2}$ Kumud Lall, ${ }^{1,2}$ M. Charles Liberman, ${ }^{1,2}$ and Sharon G. Kujawa ${ }^{1,2,3}$ \\ ${ }^{1}$ Department of Otology and Laryngology, Harvard Medical School, Boston, Massachusetts 02115 , and ${ }^{2}$ Eaton-Peabody Laboratories and ${ }^{3}$ Department of \\ Audiology, Massachusetts Eye and Ear Infirmary, Boston, Massachusetts 02114
}

Cochlear synaptic loss, rather than hair cell death, is the earliest sign of damage in both noise- and age-related hearing impairment (Kujawa and Liberman, 2009; Sergeyenko et al., 2013). Here, we compare cochlear aging after two types of noise exposure: one producing permanent synaptic damage without hair cell loss and another producing neither synaptopathy nor hair cell loss. Adult mice were exposed $(8-16 \mathrm{kHz}, 100$ or $91 \mathrm{~dB}$ SPL for $2 \mathrm{~h})$ and then evaluated from $1 \mathrm{~h}$ to $\sim 20$ months after exposure. Cochlear function was assessed via distortion product otoacoustic emissions and auditory brainstem responses (ABRs). Cochlear whole mounts and plastic sections were studied to quantify hair cells, cochlear neurons, and the synapses connecting them. The synaptopathic noise (100 dB) caused $35-50 \mathrm{~dB}$ threshold shifts at $24 \mathrm{~h}$. By 2 weeks, thresholds had recovered, but synaptic counts and ABR amplitudes at high frequencies were reduced by up to $\sim 45 \%$. As exposed animals aged, synaptopathy was exacerbated compared with controls and spread to lower frequencies. Proportional ganglion cell losses followed. Threshold shifts first appeared $>1$ year after exposure and, by $\sim 20$ months, were up to $18 \mathrm{~dB}$ greater in the synaptopathic noise group. Outer hair cell losses were exacerbated in the same time frame $(\sim 10 \%$ at $32 \mathrm{kHz})$. In contrast, the $91 \mathrm{~dB}$ exposure, producing transient threshold shift without acute synaptopathy, showed no acceleration of synaptic loss or cochlear dysfunction as animals aged, at least to $\sim 1$ year after exposure. Therefore, interactions between noise and aging may require an acute synaptopathy, but a single synaptopathic exposure can accelerate cochlear aging.

Key words: age-related hearing loss; auditory nerve; cochlear neuropathy; cochlear synaptopathy; noise-induced hearing loss; temporary threshold shift

\section{Introduction}

Noise exposure and aging are two common causes of hearing loss in humans, often occurring in the same ears. Traditionally, the influence of noise exposure on the ear and hearing has been viewed as time limited: exposure produces "hearing loss" (threshold elevations) and cochlear injury, with effects that appear largest at early postexposure times. Varying degrees of structural and functional recovery can be seen in the hours to weeks after exposure. This period of fairly rapid recovery is followed by one of relative stability, giving the impression that noise, once it stops, produces no progressive or delayed consequences as exposed individuals age (Institute of Medicine, 2005; American College of Occupational and Environmental Medicine, 2012).

Much of the evidence cited in support of this view is based on audiometric thresholds, which are generally good at reflecting damage to hair cells, but not damage to the sensory neurons innervating them, particularly when the neuropathy is subtotal

\footnotetext{
Received Dec. 18, 2014; revised March 14, 2015; accepted April 8, 2015.

Author contributions: S.G.K. designed research; K.A.F., P.W.C.J., K.L., and S.G.K. performed research; M.C.L. contributed unpublished reagents/analytic tools; K.A.F. and S.G.K. analyzed data; M.C.L. and S.G.K. wrote the paper.

This work was supported by grants from the National Institute on Deafness and other Communication DisordersNational Institutes of Health (Grants R01 DC08577, R01 DC0188, and P30 DC05209).

The authors declare no competing financial interests.

Correspondence should be addressed to Sharon G. Kujawa, PhD, Massachusetts Eye and Ear Infirmary, 243 Charles St., Boston, MA 02114-3096. E-mail: sharon_kujawa@meei.harvard.edu.

DOI:10.1523/JNEUROSCI.5138-14.2015

Copyright $\odot 2015$ the authors $\quad 0270-6474 / 15 / 357509-12 \$ 15.00 / 0$
}

or diffuse (Schuknecht and Woellner, 1955; Liberman et al., 1997; Kujawa and Liberman, 2009; Lobarinas et al., 2013; Sergeyenko et al., 2013; Bourien et al., 2014). Our recent work has shown that both aging and noise exposure have insidious consequences not revealed by standard threshold metrics. With respect to auditory aging, early events include diffuse loss of synapses between inner hair cells (IHCs) and cochlear nerve fibers throughout the cochlea (Sergeyenko et al., 2013). This synaptopathy is progressive, is reflected proportionately in declining neural response amplitudes, and is evident well before agerelated reductions in threshold sensitivity or hair cell numbers. Similarly, noise exposure causing robust but reversible changes in threshold sensitivity and no hair cell loss can nevertheless destroy cochlear synapses and reduce neural responses. These noiseinduced synaptopathies are visible within $24 \mathrm{~h}$ after exposure (Kujawa and Liberman, 2009; Lin et al., 2011). Although the noise-induced threshold elevations can recover by 2 weeks after exposure, IHCs remain partially denervated and neural response amplitudes are permanently reduced for cochlear frequencies showing maximum acute threshold shift, that is, those from basal (high-frequency) regions of this mechanically tuned sensory organ. Cochlear places apical to the region of acute threshold shift appear unaffected in the same postexposure timeframe.

Over the course of a human lifetime, noise exposures producing reversible threshold shifts are common from both occupational and recreational sources (Rabinowitz, 2012). Long-term or 
delayed effects of such exposure on the aging ear are poorly understood and generally viewed as insignificant. Here, in a mouse model, we examine the extent to which noise that produces reversible shifts in threshold sensitivity but permanent synaptic injury also influences subsequent cochlear aging. We contrast these outcomes with those arising after an exposure that also produces a robust temporary threshold shift but in the short term produces neither synaptic nor hair cell loss. We show that a single episode of synaptopathic noise early in life can exaggerate dramatically the loss of cochlear synapses and cochlear neurons that otherwise occurs with age and can produce delayed loss of threshold sensitivity and outer hair cells (OHCs). These findings question long-held assumptions about the stability of noise-induced cochlear injury and have important implications for public health.

\section{Materials and Methods}

Animals and groups. CBA/CaJ mice (males) were used in these studies. Animals were born and reared in our colony from inbred breeders obtained from The Jackson Laboratory. We have described the colony and the acoustic environment in which mice are raised previously (Sergeyenko et al., 2013). Here, mice entered the experimental protocol at 16 weeks of age and were assigned to one of the following groups. Group 1 (synaptopathic exposure) animals received our previously characterized, $8-16 \mathrm{kHz}, 100 \mathrm{~dB}$ SPL, $2 \mathrm{~h}$ exposure and were held for varying postexposure times from $1 \mathrm{~h}$ to 20 months before physiologic evaluation and retrieval of cochlear tissues. Group 2 (nonsynaptopathic exposure) animals received an exposure of identical frequency content and duration, but reduced level (91 dB SPL) that produced no acute synaptic loss; after exposure, they were tested and processed as for Group 1. Group 2b animals received the same exposure as for Group 2, but delivered for $8 \mathrm{~h}$; this group was studied at short postexposure times only to assess differences in acute cochlear synaptopathy. Group 3 (age-only controls) were unexposed, age-matched animals that were treated identically except for the noise and were held with exposed cage mates until final testing and processing at ages from 16 to 104 weeks, encompassing the range of postexposure holding times. All procedures were approved by the institutional animal care and use committee of the Massachusetts Eye and Ear Infirmary.

Acoustic overexposures. Awake mice were placed unrestrained in a subdivided cage with one mouse per division. Noise stimuli were created by a waveform generator (model WGI; Tucker-Davis Technologies), bandpass filtered $(8-16 \mathrm{kHz},>60 \mathrm{~dB} /$ octave slope; Frequency Devices), amplified (D-75 power amplifier; Crown Audio) and delivered (compression driver; JBL) via an exponential horn projecting into a reverberant tabletop exposure chamber with the subdivided cage suspended directly below. Before each exposure, noise levels were calibrated to one of the target SPLs (100 or $91 \mathrm{~dB}$ ).

Physiology: distortion product otoacoustic emissions and auditory brainstem responses. Physiologic tests were conducted on anesthetized mice (ketamine $100 \mathrm{mg} / \mathrm{kg}$ and xylazine $10 \mathrm{mg} / \mathrm{kg}$, i.p.) in an acoustically and electrically shielded, heated chamber. All testing was conducted using a National Instruments PXI-based system with 24-bit input/output boards controlled by a custom LabView-based software program. Sound sources consisted of two miniature dynamic earphones (CDMF15008-03A; CUI). A condenser microphone (FG-23329-PO7; Knowles) coupled to a probe tube measured sound pressure in the ear canal. A small V-shaped incision was made in the cartilaginous portion of the external ear canal to facilitate viewing and confirmation of a healthy tympanic membrane and to optimize placement of the acoustic system.

Auditory brainstem responses (ABRs) and distortion product otoacoustic emissions (DPOAEs) were recorded for all animals. Tone burst ABRs ( $0.5 \mathrm{~ms}$ rise-fall, $5 \mathrm{~ms}$ duration, $30 / \mathrm{s}$, alternating polarity) were measured as functions of increasing stimulus level ( $5 \mathrm{~dB}$ steps) at logspaced frequencies from 5.6 to $45.2 \mathrm{kHz}$ using subdermal needle electrodes at the vertex and ventrolateral to the pinna, with a ground electrode at the base of the tail. Responses were amplified $(10,000 \times)$, filtered (0.3-3 kHz), and averaged (1024 samples/level). Threshold was determined as the lowest level at which a repeatable Wave 1 could be identified. Peak-to-peak Wave 1 amplitude was determined using an offline analysis program. DPOAEs were recorded at $2 f_{1}-f_{2}$ in response to two primary tones, $f_{1}$ and $f_{2}$, with $f_{2}$ equal to the frequencies used in $\mathrm{ABR}$ testing, $f_{2} / f_{1}=1.2$ and $\mathrm{L} 2=\mathrm{L} 1-10 \mathrm{~dB}$, both incremented together in $5 \mathrm{~dB}$ steps. At each level combination, the amplitudes of the DPOAE responses at $2 f_{1}-f_{2}$ were captured from ear canal pressure measurements, and, after spectral and waveform averaging, were analyzed, offline, as responsegrowth functions. Iso-DPOAE contours were interpolated from the growth functions and used to determine the $f_{2}$ level required to elicit a DPOAE of $-5 \mathrm{~dB}$ SPL at each frequency, which was defined as threshold.

Histology. Anesthetized mice were transcardially perfused with $4 \%$ paraformaldehyde in $0.1 \mathrm{M}$ phosphate buffer, followed by an additional intralabyrinthine perfusion through the oval and round windows of both cochleas. One cochlea was used for immunostained epithelial whole mounts and the other for osmium-stained, plastic-embedded sections. Cochleas destined for immunostaining underwent an additional $1 \mathrm{~h}$ postfixation in $4 \%$ paraformaldehyde and were then decalcified in $0.12 \mathrm{M}$ EDTA for up to $48 \mathrm{~h}$. Microdissected pieces were immunostained with antibodies to the following: (1) C-terminal binding protein 2 (mouse anti-CtBP2; BD Biosciences, used at 1:200), (2) myosin-VIIa (rabbit anti-myosin-VIIa; Proteus Biosciences; used at 1:200), and (3) GluA2 (mouse anti-glutamate receptor 2; Millipore; used at 1:2000) with appropriate secondary antibodies coupled to Alexa Fluors in the red, blue, and green channels. Cochleas used for spiral ganglion analysis were postfixed in $2 \%$ formaldehyde and $2 \%$ glutaraldehyde in $0.1 \mathrm{~m}$ phosphate buffer overnight, decalcified in $0.12 \mathrm{M}$ EDTA for several days, rinsed in phosphate buffer, and osmicated ( $1 \%$ osmium tetroxide) for $45 \mathrm{~min}$. Tissues were then rinsed $\left(0.1 \mathrm{~m}\right.$ phosphate buffer and $\left.\mathrm{dd}_{2} \mathrm{O}\right)$, dehydrated, and embedded in Araldite in a stereotyped orientation for serial sectioning (10 $\mu \mathrm{m}$ sections, parallel to the modiolus) using a Leica RM2255 microtome. Sections were mounted in Permount on microscope slides for quantification.

Cochlear mapping and hair cell and synaptic counts. Immunostained cochlear pieces were measured and a cochlear frequency map was computed (Müller et al., 2005) to associate structures to relevant frequency regions using a custom plug-in to ImageJ. Confocal $z$-stacks of the 5.6, $11.3,22.6$, and $32 \mathrm{kHz}$ areas were collected using a Leica TCS SP2 or SP5. Two adjacent stacks were obtained (78 $\mu \mathrm{m}$ of cochlear length per stack) at each target frequency, spanning the cuticular plate to the synaptic pole of $\sim 10$ hair cells (in $0.25 \mu \mathrm{m} z$-steps). Images were collected in a $1024 \times$ 512 raster using a high-resolution, oil-immersion objective (SP2: 100 $\times$, numerical aperture 1.4; SP5: $63 \times$, numerical aperture 1.3 ) and digital zoom (SP2: $2 \times$; SP5: $3.17 \times$ ). Images were loaded into an imageprocessing software platform (Amira; VISAGE Imaging), where IHCs were quantified based on their CtBP2-stained nuclei and synaptic ribbons (with or without paired glutamate receptor patches or terminals) could be counted using 3D representations of each confocal $z$-stack. These synaptic associations were determined using custom software that calculated and displayed the $x-y$ projection of the voxel space within 1 $\mu \mathrm{m}$ of each ribbon's center (Liberman et al., 2011).

OHCs were identified in the same epithelial regions using a Nikon Eclipse E800 with a $40 \times$, numerical aperture 0.95 objective. OHCs were counted separately for each $\mathrm{OHC}$ row within a $290 \mu \mathrm{m}$ viewing field. $\mathrm{OHC}$ ribbons were counted in subsets of exposed and unexposed animals, spanning the range of ages studied.

Spiral ganglion cell quantification. Spiral ganglion neurons were quantified at four corresponding cochlear regions: 5.6, 11.3, 22.6, and $32 \mathrm{kHz}$. One section was analyzed in each cochlear region, selected to be precisely in the middle of that half-turn of the cochlear spiral. Rosenthal's canal of this section was live-imaged using DIC optics on a Nikon E600 microscope with a digital camera interfaced to Neurolucida software (version 11.0; MBF Bioscience). At $20 \times$, the continuous tracing function was used to create a closed contour (outline) of the area of Rosenthal's canal. At $40 \times$, while rolling the focus to view the entire thickness of the section, the software was used to place a marker at the $x-y$ position of each visible ganglion cell nucleolus. The data file (consisting of the outline of each area and the markers within it) was then opened in Neurolucida Explorer 

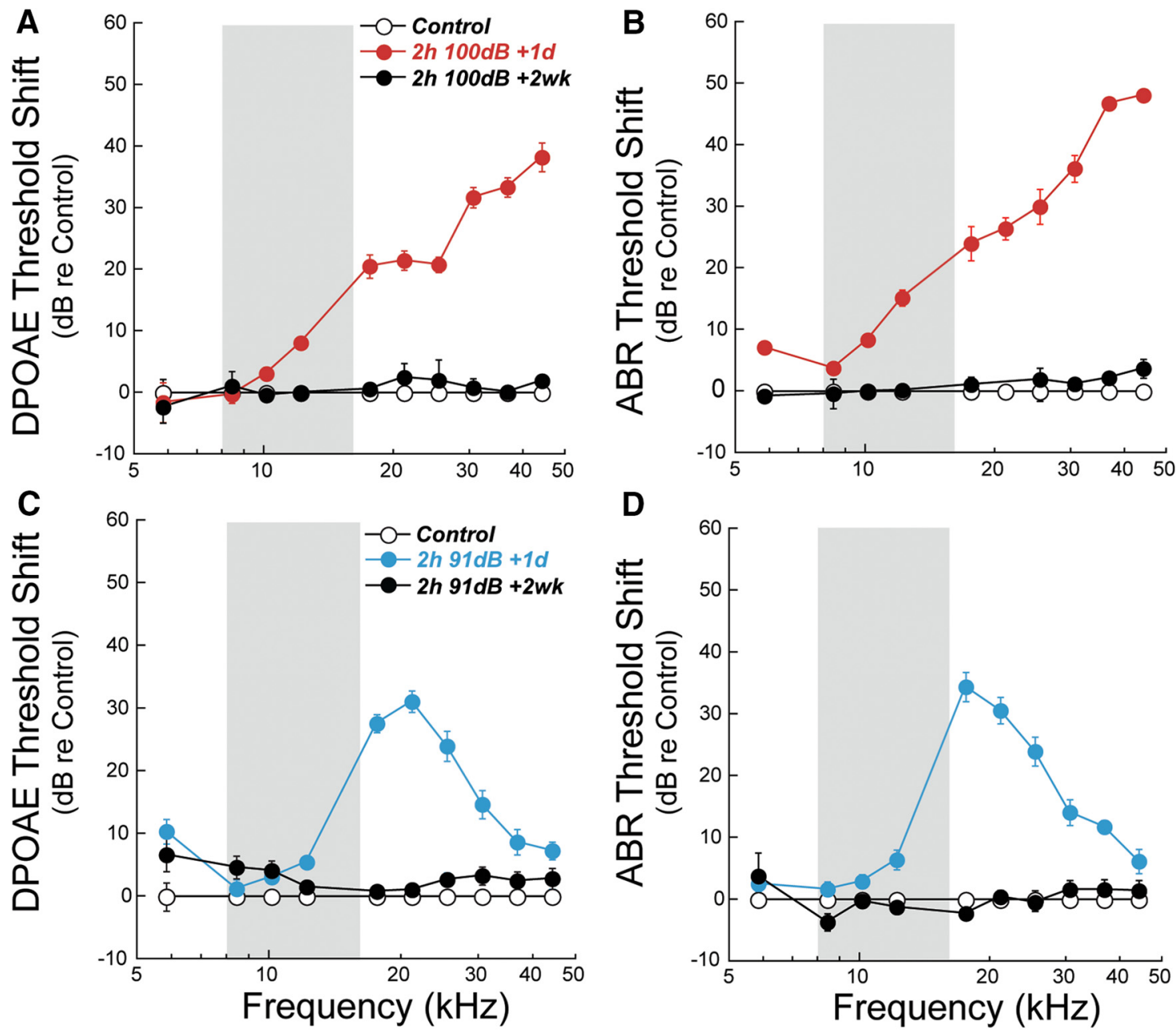

Figure 1. Noise-induced threshold shifts. In 16-week-CBA/CaJ mice, exposure to an octave-band noise ( $8-16 \mathrm{kHz})$ at $100 \mathrm{~dB}$ SPL for $2 \mathrm{~h}$ produces large ( $40-50 \mathrm{~dB}$ at $24 \mathrm{~h}$ ), but temporary, threshold shifts in both DPOAEs $(\boldsymbol{A})$ and ABRs $(\boldsymbol{B})$. The same noise band at $91 \mathrm{~dB}$ SPL for $2 \mathrm{~h}$ produces $\sim 30 \mathrm{~dB}$ TTS at $24 \mathrm{~h}$ after exposure, more restricted in frequency than after $100 \mathrm{~dB}$ noise, with maximum damage shifted to lower frequencies $(\boldsymbol{C}, \boldsymbol{D})$. For both exposures, DPOAE and ABR Wave 1 thresholds recover to control levels by 2 weeks. Data are means \pm SE. Group sizes were as follows: 16 week unexposed (15); exposed $100 \mathrm{~dB}, 2 \mathrm{~h}$ - held $24 \mathrm{~h}$ (14), held 2 week (15); exposed $91 \mathrm{~dB}, 2 \mathrm{~h}$ - held $24 \mathrm{~h}$ (11), held 2 week (10). The gray bar denotes the pass band of the noise-exposure stimulus.

(MBF Bioscience), the contour analysis function of which yielded the area of the outlined region in square micrometers. Density is expressed as SGNs/10,000 $\mu \mathrm{m}^{2}$.

\section{Results}

Patterns of acute threshold shift and initial recovery

Recent work suggests that cochlear synapses, not sensory cells, are most vulnerable to acoustic injury and aging (Kujawa and Liberman, 2009; Sergeyenko et al., 2013). Young adult ears receiving exposures producing only temporary threshold shift (TTS) and no hair cell loss can show an immediate and permanent loss of synapses between cochlear nerve terminals and IHCs. Here, we investigated whether such noise exposures can nevertheless influence the vulnerability of the ear to subsequent age-related changes. For comparison, we evaluated a synaptopathic exposure producing immediate and irreversible loss of cochlear nerve synapses and a less intense exposure that did not produce any immediate synaptopathy (or hair cell loss), although it also produced a significant TTS.

To produce acute synaptopathy, we presented an octave-band noise in the middle of the mouse hearing range $(8-16 \mathrm{kHz})$ at 100 $\mathrm{dB}$ SPL for $2 \mathrm{~h}$ (Kujawa and Liberman, 2009). In the present series, this exposure produced maximum threshold shifts of 35-50 dB when measured in DPOAEs and ABRs at $24 \mathrm{~h}$ after exposure (Fig. $1 A, B$ ). Acute shifts increased with increasing frequency above the exposure band. The shifts were slightly greater when measured in ABRs than in DPOAEs and they recovered by 2 weeks after exposure.

For comparison, we wanted a group that experienced the stress of a TTS-producing acoustic overexposure but at a level low enough that neither hair cell loss nor cochlear nerve synaptopathy was observed in the acute postexposure period. Using the same noise band and exposure duration, we progressively halved its energy (reducing level in $3 \mathrm{~dB}$ steps) until we identified a level (91 dB SPL) that produced no acute loss of synapses (see below). This "nonsynaptopathic" exposure produced maximum threshold shifts of $30-35 \mathrm{~dB}$ at $24 \mathrm{~h}$ after exposure (Fig. 1C,D). Threshold shifts from the lower-level exposure were more restricted in frequency and peaked at a lower frequency $(\sim 20-22 \mathrm{kHz})$ than for the same noise band presented at the higher level. Thresholds measured by both ABRs and DPOAEs also recovered to baseline values by 2 weeks after exposure.

Patterns of acute and progressive synaptic loss and spiral ganglion cell loss

All of the myelinated sensory fibers in the cochlear nerve contact exclusively the IHCs, as schematized in Figure 2A (Spoendlin, 

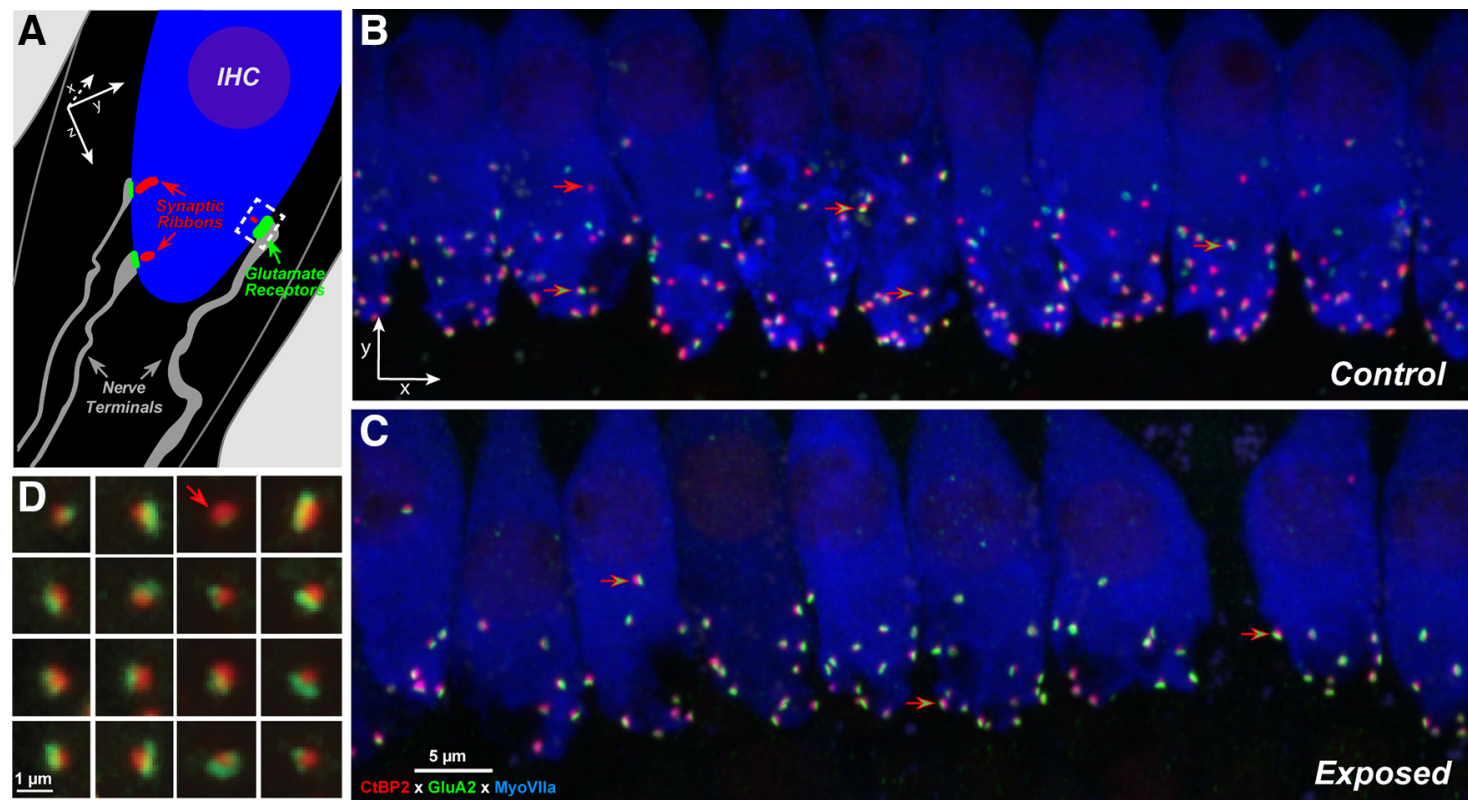

Figure 2. Confocal imaging and quantification of IHC synapses. $A$, Schematic of the IHC area showing the presynaptic and postsynaptic elements we immunostain to assess synaptopathy. The white box indicates the region displayed in each thumbnail image in $\boldsymbol{D} . \boldsymbol{B}, \boldsymbol{C}$, Confocal images of IHC synapses from the $32 \mathrm{kHz}$ region of an unexposed, 16-week-old control (B) and an exposed ( $\boldsymbol{C}$; 2 weeks after $100 \mathrm{~dB}, 2 \mathrm{~h}$ exposure) cochlea immunolabeled for presynaptic ribbons (CtBP2-red), postsynaptic receptor patches (GluA2-green), and IHCs (mysoin VIla, blue). In unexposed ears, whether young or old (16 week shown in $\boldsymbol{B}$ ), virtually all immunostained ribbons are paired with a glutamate receptor patch (red-fill green arrows); in exposed ears, some "orphan" ribbons (red arrows in $($ and $\boldsymbol{D}$ ) are unpaired with postsynaptic puncta. $\boldsymbol{D}$, High-power reprojections in the $z-y$ plane were used to quantify the numbers of orphan ribbons.

1972). The normal synapse between an IHC and a cochlear nerve terminal comprises a presynaptic ribbon with its associated halo of neurotransmitter-containing vesicles (Liberman, 1980; Liberman et al., 1990) and a postsynaptic active zone with glutamate receptors for the released neurotransmitter (Matsubara et al., 1996; Ruel et al., 2007; Meyer et al., 2009; Grant et al., 2010). To identify and count synapses on IHCs, we used antibodies to $\mathrm{CtBP} 2$, a prominent component of the presynaptic ribbon (Khimich et al., 2005), and to GluA2 subunits to identify postsynaptic receptor patches (Matsubara et al., 1996). Synapses were defined as juxtaposed pairs of CtBP2- and GluA2-positive puncta, as schematized in Figure $2 A$. Maximum confocal projections from unexposed (Fig. 2B) and exposed (Fig. 2C) IHCs reveal the loss of synapses seen immediately after exposure. To allow unambiguous identification of synapses (i.e., ribbons with closely apposed receptor patches) versus "orphan" ribbons or receptor patches, we used custom software that displays the voxel space from the confocal $z$-stack within a small cube centered on each immunostained ribbon (or receptor patch), as shown in Figure 2D.

In the present study, synapses were counted in four cochlear regions, including zones of minimal ( 5.6 and $11.3 \mathrm{kHz}$ ) and maximal ( 22.6 and $32 \mathrm{kHz}$ ) acute threshold elevation from the TTSproducing noise. Synapse numbers declined gradually with age in all four regions (Fig. 3A-D), as reported previously (Sergeyenko et al., 2013). Losses reached 15-25\%, depending on cochlear frequency, by 104 weeks of age. Immediately after the $2 \mathrm{~h}, 91 \mathrm{~dB}$ exposure, there were no synaptic losses in any cochlear regions (Fig. 3A-D). Therefore, the $91 \mathrm{~dB}$ exposure is initially nonsynaptopathic, although threshold shifts were as high as $40 \mathrm{~dB}$ when measured $24 \mathrm{~h}$ after exposure (Fig. 1). In contrast, ears exposed for $2 \mathrm{~h}$ at $100 \mathrm{~dB}$ SPL showed an immediate ( $35-55 \%$ within $1 \mathrm{~h})$ reduction in synaptic counts at the two high-frequency locations (Fig. 3C,D), as reported previously for the same exposure (Kujawa and Liberman, 2009).
In addition to this loss of synapses (paired ribbon-receptor puncta), we observed that ribbon counts per se were higher than synaptic counts when assessed $1 \mathrm{~h}$ after $100 \mathrm{~dB}$, but not $91 \mathrm{~dB}$, exposure. In normal ears, there is a nearly one-to-one pairing between ribbons and glutamate receptor patches (Figs. 2B, $4 A-$ $C)$. In the $100 \mathrm{~dB}$-exposed ears, $\sim 26 \%$ of the ribbons that remained in the maximum damage region (Fig. $4 C$ vs $A, B$ ) were "orphans" at $1 \mathrm{~h}$ after exposure. By $24 \mathrm{~h}$, this number had fallen to $\sim 8 \%$ and, by 2 weeks, virtually all remaining ribbons were once again paired with glutamate receptor patches, as in the control ears. This change in the number of GluA2 puncta could reflect a transient internalization of surface glutamate receptors, as documented previously in response to glutamate agonists in vitro or noise in vivo (Chen et al., 2007). This reversible downregulation of surface AMPA receptors may serve a protective function (Chen et al., 2007, 2009) by modulating synaptic strength.

In prior work, we followed the progression of synaptopathy after the $100 \mathrm{~dB}$ exposure for 8 weeks and saw no signs of synaptic recovery in the damaged regions (Kujawa and Liberman, 2009). Here, we followed the postexposure ears for up to 88 weeks after exposure and again saw no signs of synaptic recovery (Fig. 3). Indeed, the trend was toward ongoing synaptic degeneration. When this trend in aging $100 \mathrm{~dB}$-exposed ears is compared with the age-related synaptic decline in control ears, key differences are evident. First, despite an initial absence of apical synaptic loss in the exposed mice, the degeneration spreads apically as animals age, outpacing declines in control ears at 16 weeks after exposure and beyond (Fig. $3 A, B$ ). Second, cochlear regions with large acute losses (Fig. 3C,D) show continued age-related declines, but at a slower pace (fewer synapses lost per year) than age-only controls and also at a slower pace than in cochlear regions with minimal acute losses (Fig. $3 A, B$ ). This deceleration of ongoing synaptic loss is consistent with the idea that a subset of cochlear nerve terminals is more vulnerable to noise and to aging (Schmiedt et al., 1996; Furman et al., 2013) and that many of 

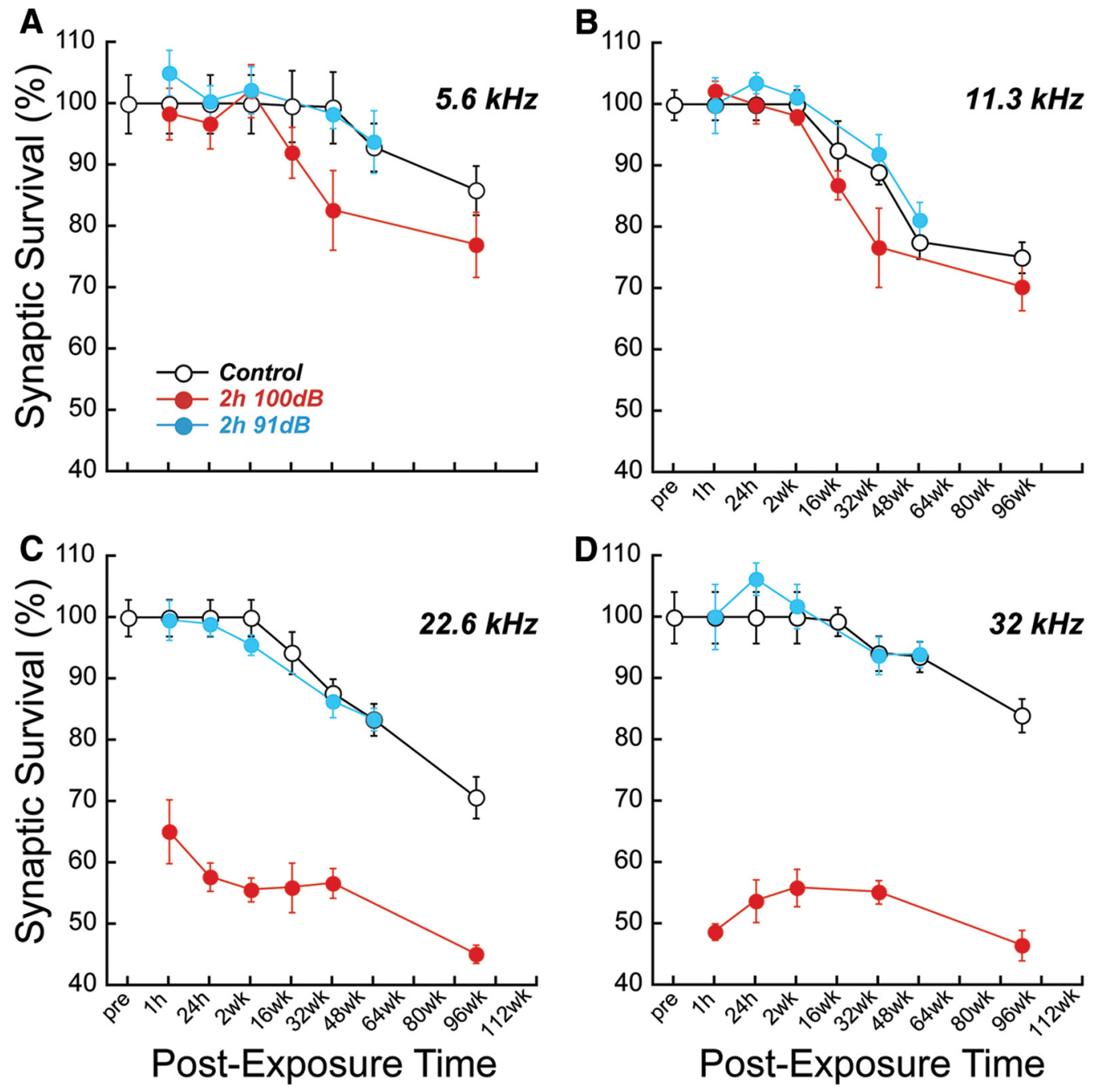

Figure 3. Age- and noise-induced synapse loss. In unexposed ears, synapse counts decline gradually with age (open symbols, $\boldsymbol{A}-\boldsymbol{D}$ ). Synaptopathic noise (red symbols, $100 \mathrm{~dB}, 2 \mathrm{~h}$ ) immediately produces $35 \%$ synapse loss in basal cochlear regions $(\boldsymbol{C}, \boldsymbol{D})$ without loss in regions of minimum TTS $(\boldsymbol{A}, \boldsymbol{B})$. With advancing age, losses spread apically, exceeding those in age-matched controls. There is no acute synapse loss for the $91 \mathrm{~dB}$ exposure (teal symbols, $\boldsymbol{A}-\boldsymbol{D}$ ) and no obvious interaction between noise and aging. Means ( $\pm \mathrm{SE}$ ) are normalized to 16 week, unexposed values. Group sizes were as follows: unexposed-16 week (15), 32 week (5), 64 week (7), 80 week (9), 104 week (6); exposed $100 \mathrm{~dB}, 2 \mathrm{~h}$ - held $1 \mathrm{~h}$ (12), $24 \mathrm{~h}$ (14), 2 week (15), 16 week (7), 48 week (5), 88 week (6); exposed $91 \mathrm{~dB}, 2 \mathrm{~h}$ - held $1 \mathrm{~h}(5), 24 \mathrm{~h}(11), 2$ week (10), 48 week (5), 64 week (6).

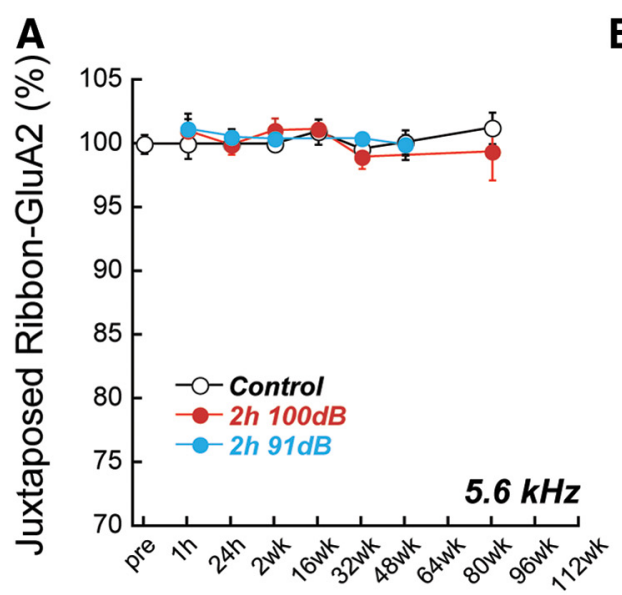

Post-Exposure Time
B

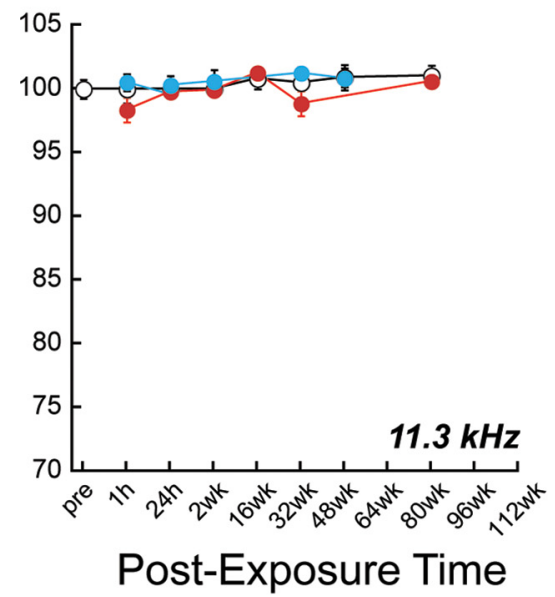

C

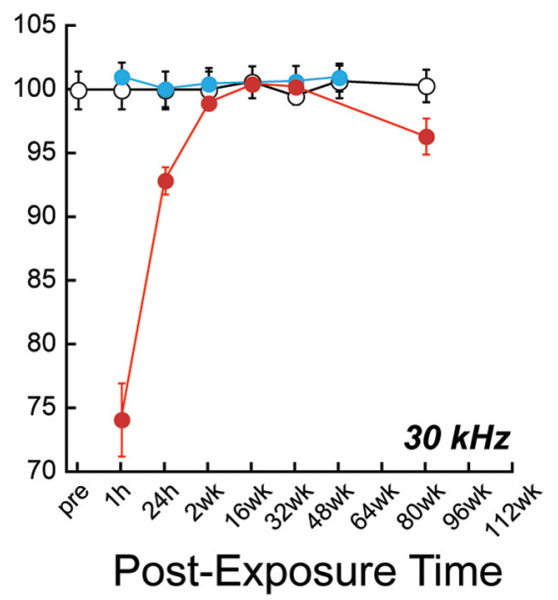

Figure 4. Transient postnoise reductions in GluA2-positive puncta. When quantified $1 \mathrm{~h}$ after synaptopathic noise, counts of GluA2-immunostained glutamate receptor patches are reduced by $>25 \%$ in the maximum damage region (cf. Cvs $\boldsymbol{A}, \boldsymbol{B}$ ). By 2 weeks after exposure, virtually all remaining ribbons again display colocalized receptor patches, as in control ears. Counts in ears receiving nonsynaptopathic exposure did not display similar, dynamic changes. Group sizes are provided in the Figure 3 legend. 
A

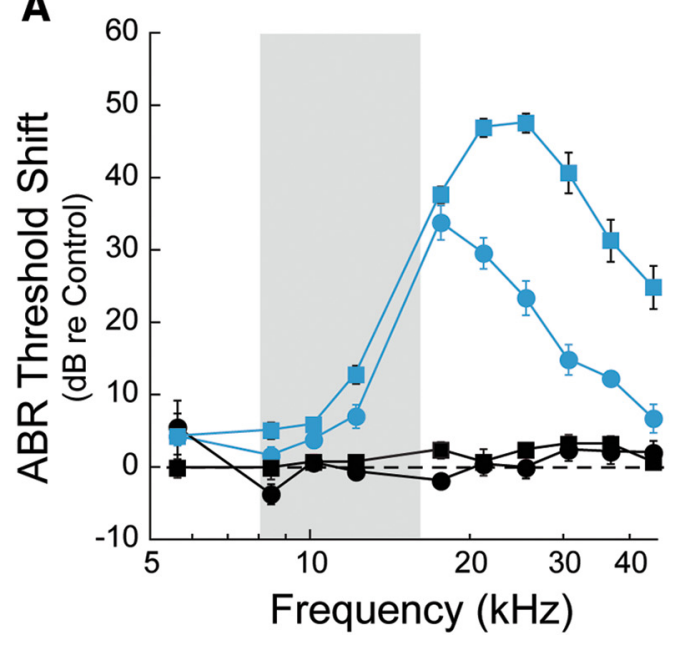

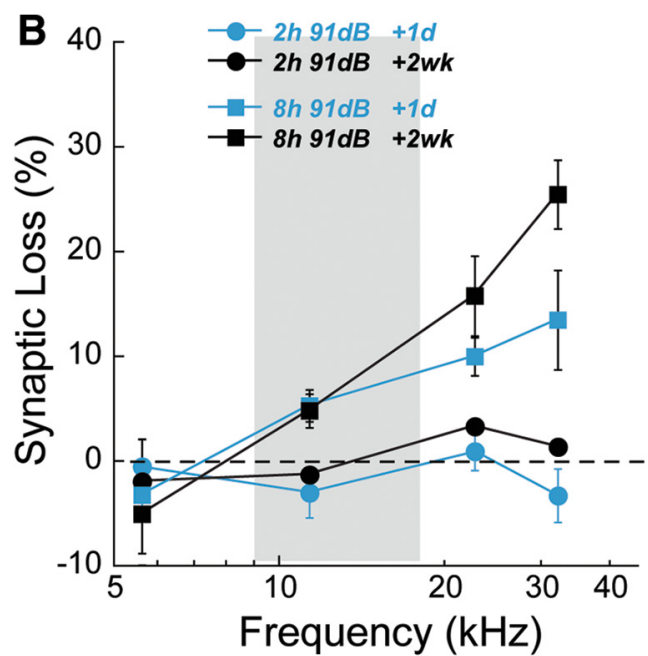

Figure 5. Nonsynaptopathic exposure becomes synaptopathic with longer duration. ABR threshold shift $(\boldsymbol{A})$ and synapse loss $(\boldsymbol{B})$ compared with 16 week controls are shown for nonsynaptopathic $(91 \mathrm{~dB}, 2 \mathrm{~h})$ and synaptopathic $(91 \mathrm{~dB}, 8 \mathrm{~h})$ exposures at $1 \mathrm{~d}$ and 2 weeks after exposure. For both metrics, longer exposure resulted in increased magnitude and basalward shift of maximum injury. Although thresholds for both exposures recover, synapse loss is persistent and displays some early progression in the highest frequency regions. Key in $\boldsymbol{B}$ applies to both panels. Group sizes were as follows: 16 week unexposed (15); exposed $91 \mathrm{~dB}, 2 \mathrm{~h}$ - held $24 \mathrm{~h}$ (11), held 2 week (10); exposed $91 \mathrm{~dB}, 8 \mathrm{~h}$ - held $24 \mathrm{~h}$ (8), held 2 week (11).

these were lost acutely with the $100 \mathrm{~dB}$ exposure, limiting further change with age. $\mathrm{OHC}$ ribbon counts in the same ears were essentially unaffected: for surviving $\mathrm{OHCs}$, ribbon losses were small and similar ( $\pm 3 \%$ of 16 week controls at $32 \mathrm{kHz}$ ) in $104-$ week-old ears with or without $100 \mathrm{~dB}$ exposure at 16 weeks (Kujawa and Liberman, 2009; Sergeyenko et al., 2013).

By design, the $2 \mathrm{~h}, 91 \mathrm{~dB}$ exposure produced no acute loss of synapses (Fig. $3 A-D$ ); however, when the same exposure was instead delivered for an $8 \mathrm{~h}$ period, the acute consequences of the noise were magnified and shifted basally (Fig. 5A,B). The longer exposure caused greater TTS at high frequencies, but shifts at 18 $\mathrm{kHz}$ and below were virtually identical for the 2 and $8 \mathrm{~h}$ exposures (Fig. 5A). There also was evidence of acute synaptopathy after the $8 \mathrm{~h}$ exposure; synaptic loss increased with cochlear frequency and appeared progressive with postexposure time, with up to $\sim 25 \%$ loss in the damage region (Fig. $5 B$ ) over the 2 week period of monitoring. These findings suggest that basal cochlear injury may be important to the generation of progressive synaptopathies (see Discussion).

We also counted spiral ganglion cells, the cell bodies of cochlear nerve fibers. Figure 6 shows images from young ( 16 weeks; Fig. 6A) and old (104 weeks; Fig. 6B) unexposed ears compared with an ear exposed ( $100 \mathrm{~dB}$ for $2 \mathrm{~h}$ ) at 16 weeks and held to the same 104 week chronological age (Fig. 6C). Cell counts, obtained in the same cochlear regions as for synapse counts, revealed proportional losses. Figure 6 shows data for $11.3 \mathrm{kHz}$, in a region of minimal age-related and noise-induced threshold elevation (Fig. $6 D$ ) and $32 \mathrm{kHz}$ in the region of maximal shifts for both (Fig. 6E). As ears aged with or without prior noise exposure, synapse loss was an excellent predictor of the ultimate loss of spiral ganglion cells. Ganglion cell losses from aging alone were modest, reaching $\sim 20 \%$ by 104 weeks in both cochlear locations. For ears with synaptopathic exposure, subsequent losses began earlier and ultimately exceeded those for age-only controls: by almost $25 \%$ at $11.3 \mathrm{kHz}$ (Fig. $6 D$ ) and by almost $40 \%$ at $32 \mathrm{kHz}$ (Fig. $6 E$ ), as shown for synapse losses in the two groups (Fig. 3 B,D). Ganglion cell counts in the nonsynaptopathic group were not different from those of unexposed, age-matched controls, at least to 64 weeks of age, consistent with the similarity in age-related synaptic losses in these two groups (Fig. 3).

\section{Patterns of acute and progressive hair cell loss}

Consistent with our previous report (Sergeyenko et al., 2013), $\mathrm{OHC}$ losses in unexposed aging ears appeared relatively late, between 1 and 2 years (Fig. 6). At 104 weeks, losses in the apicalmost region $(5.6 \mathrm{kHz}$; Fig. $7 A$ ) were $60 \%$. At middle- to highfrequency places (Fig. $7 B-D$ ), losses were $<10 \%$, although in the extreme base (not sampled here), losses also rose to $\sim 50 \%$ over the same span of ages (Spongr et al., 1997). Losses at all ages were similar across all $\mathrm{OHC}$ rows.

$\mathrm{OHCs}$ were not lost acutely after exposure to either the $91 \mathrm{~dB}$ or the $100 \mathrm{~dB}$ noise, but at $100 \mathrm{~dB}$, there was a slight exacerbation of $\mathrm{OHC}$ death at the oldest survival (Fig. $7 A-D$ ). These differences from age-matched controls were statistically significant at $32 \mathrm{kHz}$ only $(p<0.01$, Bonferroni post hoc pairwise comparisons). The loss was greatest for row 1 hair cells, the same pattern seen in the acute response to acoustic injuries that cause PTS (Robertson and Johnstone, 1980; Saunders et al., 1991). IHC loss was minimal $(\sim 5 \%)$ at all ages in all cochlear regions and was not exaggerated by prior noise, at least over the range of postexposure times sampled here (Fig. $7 A-D)$.

Age-related decline of cochlear function in noise-exposed and control ears

Noise exposure producing TTS and acute loss of IHC synapses has immediate and delayed effects on cochlear function. Synaptic loss is reflected in permanently reduced suprathreshold amplitudes of cochlear neural responses, because communication between hair cells and cochlear nerve fibers is permanently interrupted. Suprathreshold growth of response amplitude was assessed at all postexposure times and frequencies of threshold monitoring by both DPOAEs and ABRs. Figure 8 compares responses from age-only ears versus ears that were exposed and then aged. We focus here on the maximum damage region for the synaptopathic, $2 \mathrm{~h} 100 \mathrm{~dB}$ exposure $(32 \mathrm{kHz}$; Fig. $8 \mathrm{~A}, B)$ and for the nonsynaptopathic, $2 \mathrm{~h} 91 \mathrm{~dB}$ exposure (22 kHz; Fig. 8C,D). Several key patterns emerged: In age-only ears (open symbols) DPOAEs changed little with time; amplitude-level functions (Fig. $8 \mathrm{~A}, \mathrm{C}$ ) are largely overlapping except at $32 \mathrm{kHz}$ where 104 week animals showed a $\sim 15 \mathrm{~dB}$ rightward shift, suggesting $\mathrm{OHC}$ dysfunction. In comparison, amplitudes of ABR Wave 1 (Fig. $8 B, D$ ) 

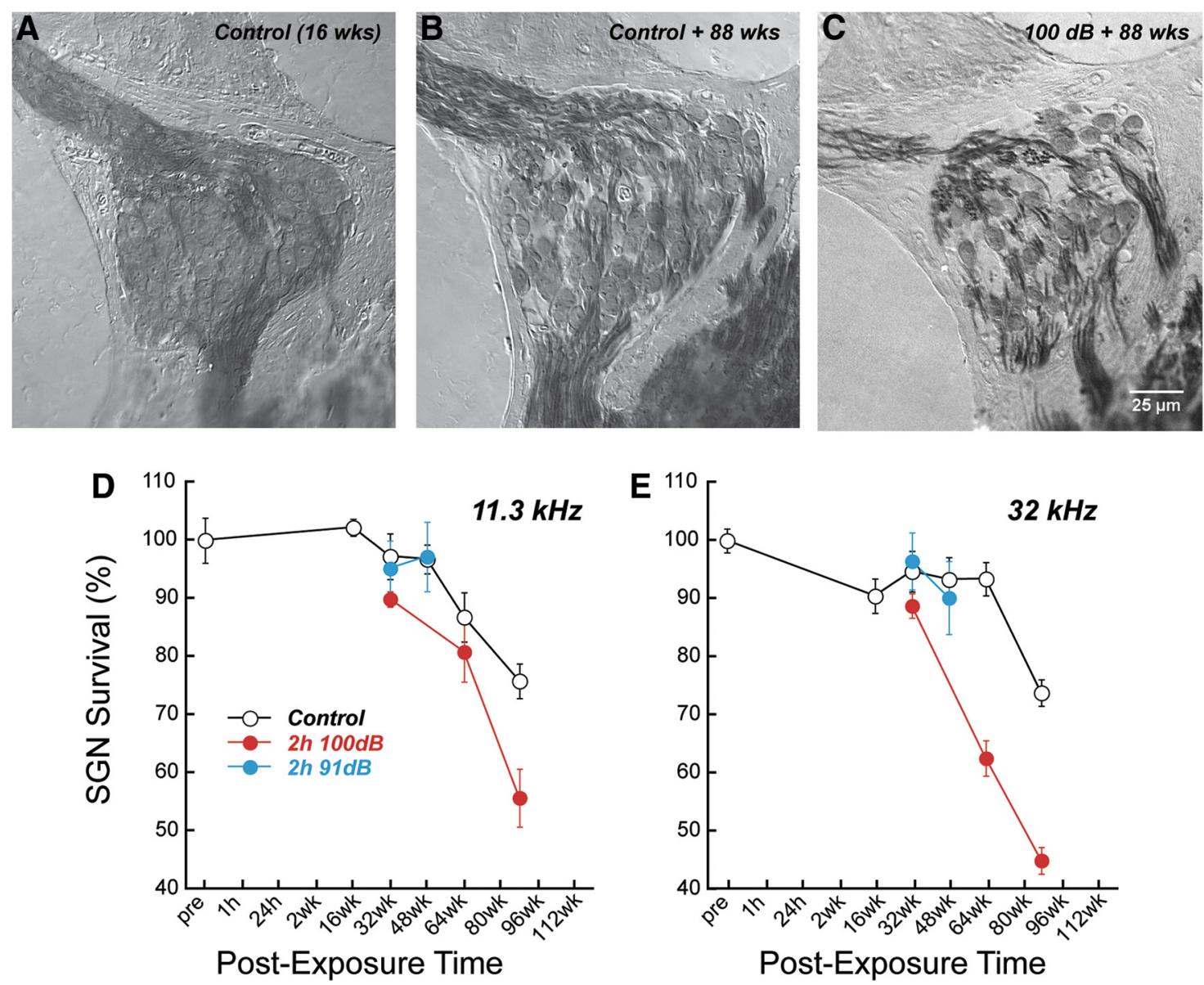

Figure 6. Synaptopathic noise exposure exacerbates spiral ganglion cell loss as animals age after noise. Representative cochlear sections from the $32 \mathrm{kHz}$ region of control $(\boldsymbol{A}: 16$ weeks chronological age, unexposed); control + 88 weeks (B:104 weeks chronological age, unexposed); and $100 \mathrm{~dB}+88$ weeks (C:exposed at 16 weeks, held 88 weeks to 104 weeks chronological age) showing exaggerated loss of spiral ganglion cells in ears aged after exposure to synaptopathic noise. Scale bar in Capplies to all SGN images. Cell counts in groups (means \pm SE, group sizes are provided in Fig. 3 legend) with and without prior noise are displayed at two frequencies: $11.3 \mathrm{kHz}$ (D) and $32 \mathrm{kHz}$ (E).

declined progressively, beginning well before $\mathrm{OHC}$ loss and greatly exceeding changes in the DPOAEs. Again, changes were largest at the higher frequency.

After exposure, response amplitudes for both metrics were acutely reduced in the TTS region (filled red symbols in Fig. 8). DPOAE amplitudes recovered to control levels by 2 weeks for both exposures (Fig. $8 \mathrm{~A}, \mathrm{C}$ ). Synaptopathic, but not nonsynaptopathic, exposure caused permanent reductions in ABR Wave 1, the summed activity of cochlear nerve fibers (Fig. $8 B$ vs $D$ ). As animals aged after synaptopathic exposure, ABR amplitude reductions were exaggerated compared with age-only controls (compare filled vs open symbols in Fig. $8 B$ ). At the oldest age, exaggerated declines also are evident in the DPOAEs (Fig. $8 A$ ), suggesting progressive injury to $\mathrm{OHC}$ function. For the nonsynaptopathic exposure, neural amplitude reductions were not exaggerated compared with age-only ears (overlapping open and filled symbols), at least to 48 weeks after exposure (Fig. $8 D$ ).

In contrast to the early appearance of age-related synaptic loss (Fig. 3) and Wave 1 amplitude decline (Fig. 8), age-related onset of threshold elevation occurs relatively late in CBA/CaJ mice. Here, age-only controls demonstrated small, mid- to highfrequency threshold shifts through 104 weeks of age (data not shown; Sergeyenko et al., 2013). After noise-induced TTS, once thresholds had recovered to control levels (2 weeks after exposure), they remained relatively stable compared with controls for nearly one year. By the longest postexposure time (88 weeks), animals receiving the $100 \mathrm{~dB}$ noise showed slightly larger threshold shifts, greater by ABRs $(\sim 10-18 \mathrm{~dB})$ than DPOAEs $(\sim 5-10$ $\mathrm{dB}$ ), as shown in Figure 9 for data at $32 \mathrm{kHz}$. Group differences reached significance at $11.3,22.6$, and $32 \mathrm{kHz}$ for both DPOAEs and ABRs ( $p<0.01$, Bonferroni post hoc pairwise comparisons). Thresholds for animals receiving the nonsynaptopathic exposure were not different from controls, at least to 64 weeks (data not shown).

\section{Discussion}

Synaptopathic versus nonsynaptopathic exposures and the relation to TTS magnitude

Hair cells have long been considered to be the most vulnerable elements in the inner ear and the primary targets of damage after acoustic overexposure (Bohne and Harding, 2000). However, recent work shows that, in both noise-exposed and aging ears, synapses between IHCs and cochlear nerve terminals degenerate long before the hair cells themselves (Kujawa and Liberman, 2009; Sergeyenko et al., 2013). In ears that age without prior acoustic injury, the diffuse loss of afferent synapses on IHCs is gradually progressive throughout life and throughout the cochlea (Sergeyenko et al., 2013). After noise, the loss is sudden and most severe in the cochlear frequency region where the acute threshold shift is maximal. In either case, loss of a cochlear nerve fiber's sole synaptic connection to the sensory cell renders it unresponsive to sound. However, thresholds, long considered the gold standard met- 
A

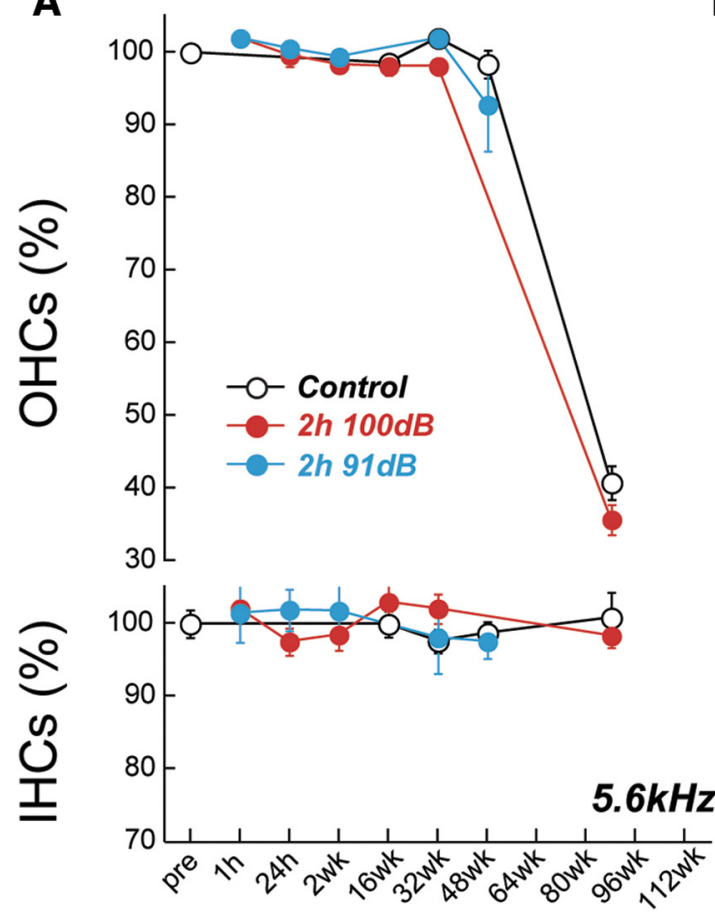

B

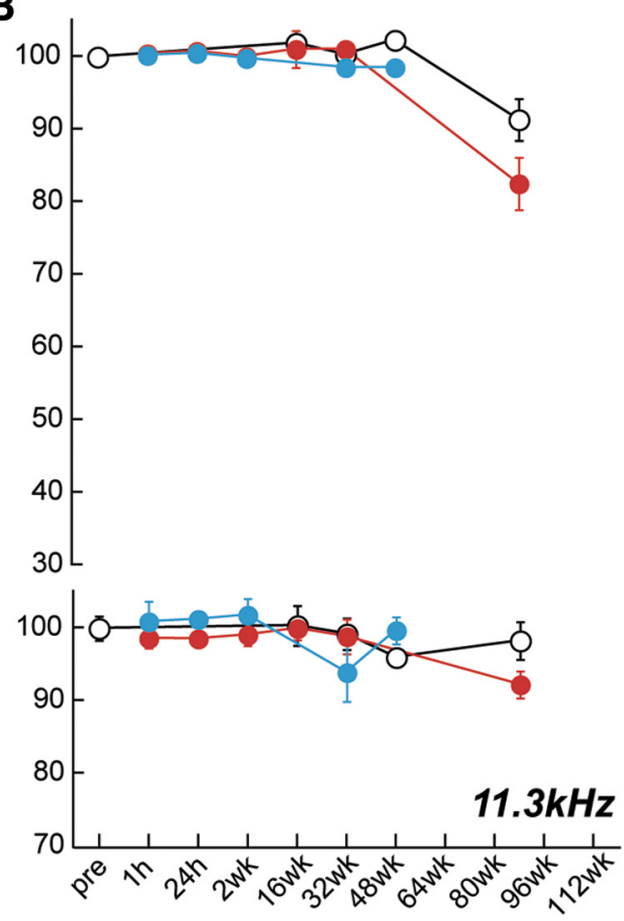

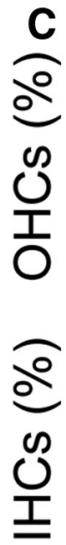

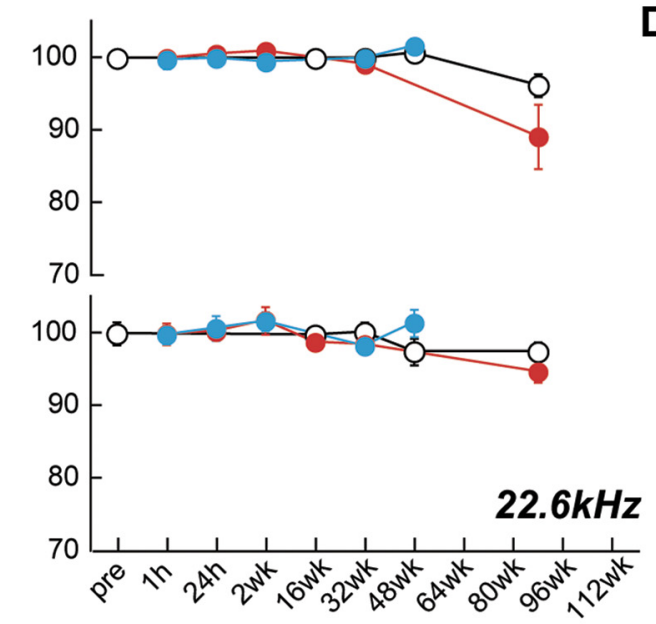

Post-Exposure Time
D

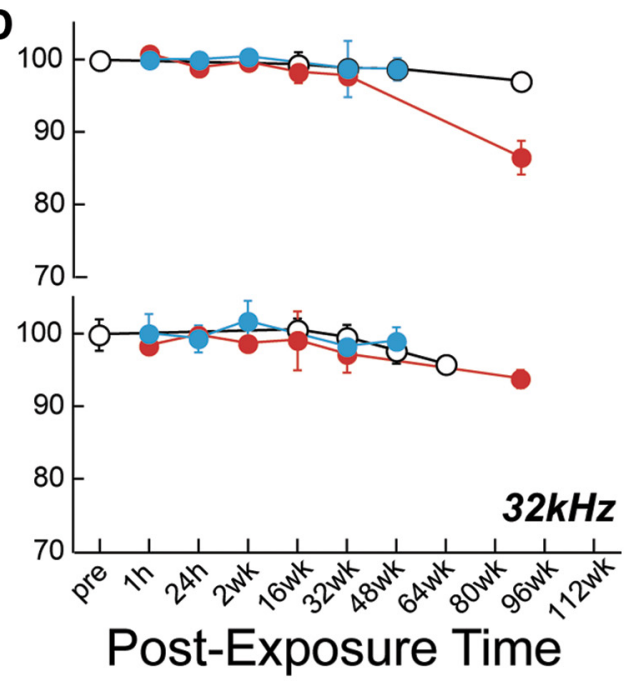

Figure 7. Synaptopathic noise exposure exacerbates $\mathrm{OHC}$ loss in aging ears. In unexposed ears, age-related $0 \mathrm{HC}$ loss begins late, and, except at $5.6 \mathrm{kHz}$, is minimal ( $\sim 5 \%$ ) and similar in all rows. Exaggerated $\mathrm{OHC}$ loss was a late consequence of synaptopathic noise ( $100 \mathrm{~dB}, 2 \mathrm{~h}$ ), whereas nonsynaptopathic noise ( $91 \mathrm{~dB}$ ) produced no additional hair cell loss through 48 weeks after exposure. Here, we compare counts of first-row $0 \mathrm{HCs}$ compared with 16 week unexposed controls at four cochlear frequencies for the two exposure groups and age-matched controls $(\boldsymbol{A}-\boldsymbol{D}$, upper panels of each). IHC loss was $<5 \%$ at all frequencies for all groups at all ages ( $\boldsymbol{A}-\boldsymbol{D}$, lower panels of each). Data are means \pm SE; group sizes are provided in Figure 3 legend.

ric of noise-induced and age-related damage, are insensitive to diffuse synaptopathy; therefore, the hearing loss that results is "hidden" (Schaette and McAlpine, 2011; Bharadwaj et al., 2014; Plack et al., 2014).

In the current studies, the $91 \mathrm{~dB}, 2 \mathrm{~h}$ exposure differed by design from the $100 \mathrm{~dB}, 2$ h exposure in that it caused no acute synaptopathy. DPOAE and ABR thresholds, as well as suprathreshold amplitudes, recovered by 2 weeks and remained identical to age-only controls for at least 1 year after exposure. Importantly, ongoing loss of synapses and ganglion cells in these ears was not different from age-only controls. Data from this nonsynaptopathic exposure thus provide several key insights. First, they provide an important control for other, stress-induced differences between exposed and unexposed animals; for example, changes in circulating glucocorticoid levels that might be induced by any $2 \mathrm{~h}$, TTS-producing noise exposure regardless of the cochlear injury elicited (Canlon et al., 2007; Peppi et al., 2011). Second, the finding that ABR amplitudes recover in TTS ears lacking noise-induced synaptopathy is an important demonstration that the Wave 1 amplitude assay can provide a specific, as well as sensitive, reflection of underlying synaptic health. Third, the data provide evidence that, although synapse loss is a primary and early consequence of noise exposure, not all TTS-producing exposures are synaptopathic.

Our initial approach to the study of noise-induced cochlear synaptopathy was to create a severe TTS "on the border" of reversibility wherein even a few decibels of increase in exposure level would have caused permanent threshold shift and hair cell 


\section{$2 h 100 d B$}
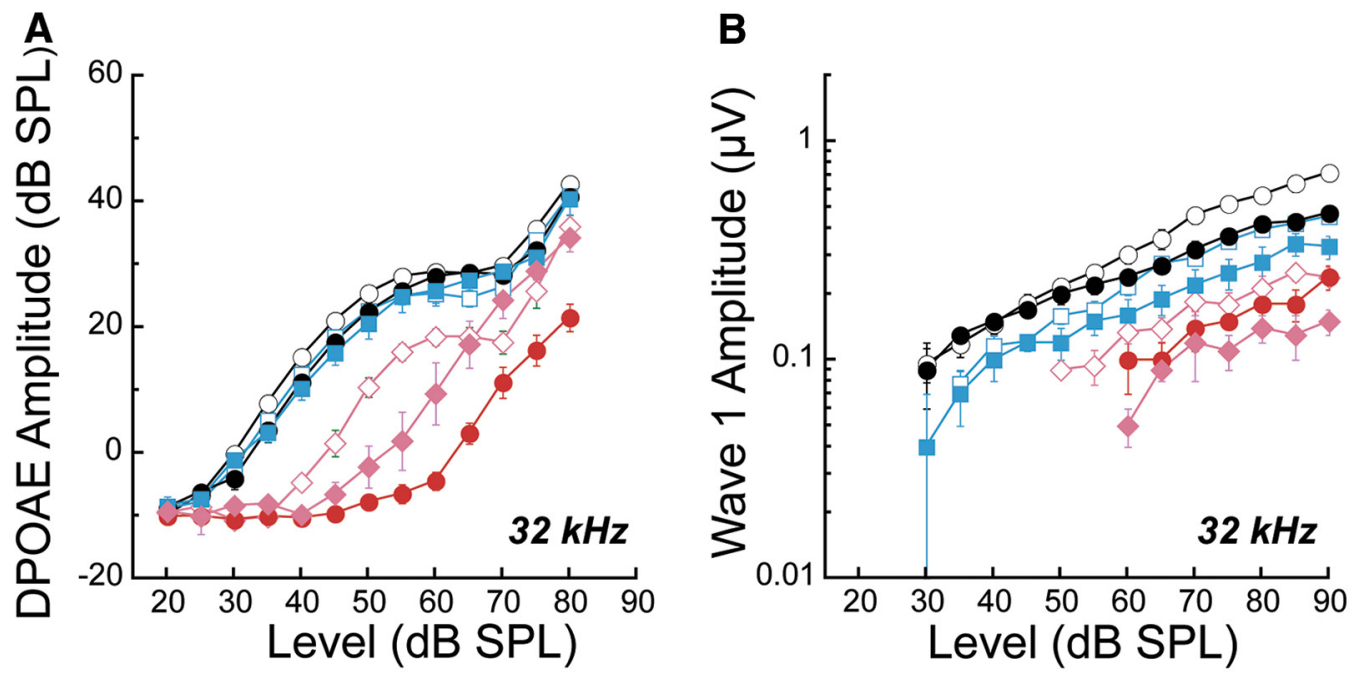

\section{2h $91 d B$}
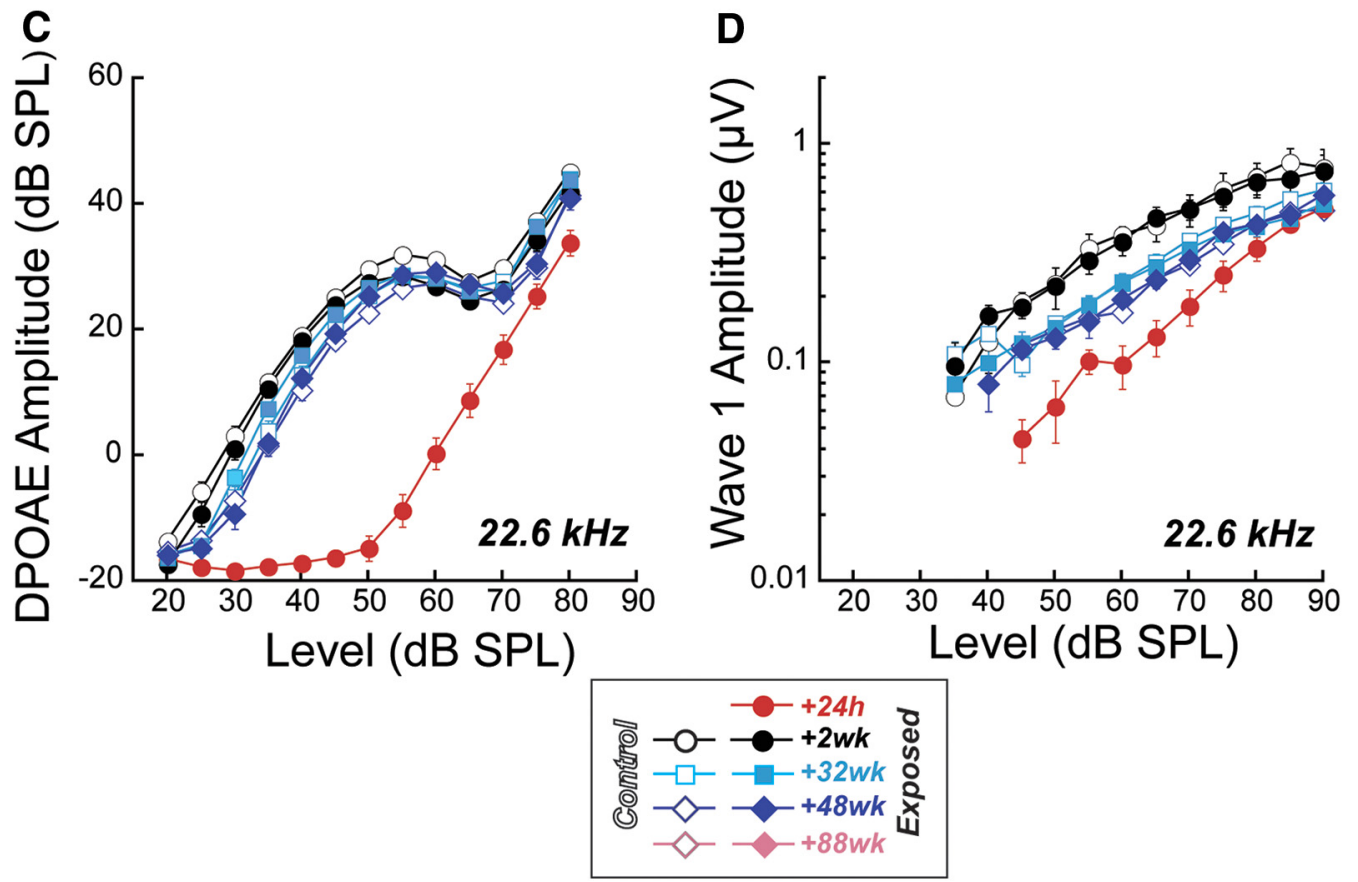

Figure 8. Synaptopathic noise exposure exacerberates ABR amplitude reductions in aging ears. DPOAE and ABR Wave 1 response growth is compared in aging ears with and without prior noise exposure. DPOAE amplitude reductions are small in unexposed ears (controls, open symbols in $\boldsymbol{A}, \boldsymbol{C}$ ) until the oldest age $(\boldsymbol{A})$. In contrast, Wave 1 in unexposed ears ( $\boldsymbol{B}, \boldsymbol{D})$ shows progressive decline throughout the lifespan. Noise-exposed ears are compared at the frequency of maximum TTS for each exposure. Although thresholds recovered, synaptopathic noise ( $100 \mathrm{~dB}, 2 \mathrm{~h}$ ) exaggerated the $\operatorname{ABR}(\boldsymbol{B})$, but not DPOAE $(\boldsymbol{A})$, amplitude declines at all postexposure time points, with a subset plotted here, for clarity. After nonsynaptopathic noise $(91 \mathrm{~dB}, 2 \mathrm{~h}), \mathrm{DPOAE}$ and ABR Wave 1 responses were similar to those in control ears, at least to 48 weeks after exposure. Key in $\boldsymbol{A}$ applies to all panels. Data are means \pm SE; group sizes are provided in Figure 3 legend.

damage (Kujawa and Liberman, 2009). In the adult (16 week) $\mathrm{CBA} / \mathrm{CaJ}$ mouse, this was achieved with $100 \mathrm{~dB}, 2 \mathrm{~h}$ exposure to a noise band that produced maximum reversible threshold elevation at high frequencies and an $\sim 40 \%$ loss of synapses in corresponding cochlear regions. Here, comparing effects of this $100 \mathrm{~dB}$ exposure with an exposure at a lower sound level shows that the degree of synaptopathy does not relate in a simple way to the TTS magnitude (Fig. 10). At $32 \mathrm{kHz}$, where the TTS was larger for 100 $\mathrm{dB}$ exposure than for $91 \mathrm{~dB}$ exposure ( $35 \mathrm{vs} 15 \mathrm{~dB}$, respectively), the synaptic loss also was much larger ( $40 \%$ loss vs no loss, respectively). However, at $22 \mathrm{kHz}$, where the TTSs were virtually identical, the synaptic degeneration was very different (40\% loss vs no loss, respectively). The same trend can be seen by comparing the $2 \mathrm{~h}$ versus $8 \mathrm{~h}$ exposures at $91 \mathrm{~dB}$ : threshold shifts through $\sim 18 \mathrm{kHz}$ are the same, but the synaptopathy diverges (Fig. 5). It may be significant that, in both comparisons, the exposure producing the greater spread of TTS toward the cochlear base produced the greater loss of cochlear nerve synapses.

We wondered whether there was a trading relation between time and intensity in the generation of the synaptic loss. Commonly, "exchange rates" are used to describe relationships between exposure level and time predicted to yield equivalent noise 
A

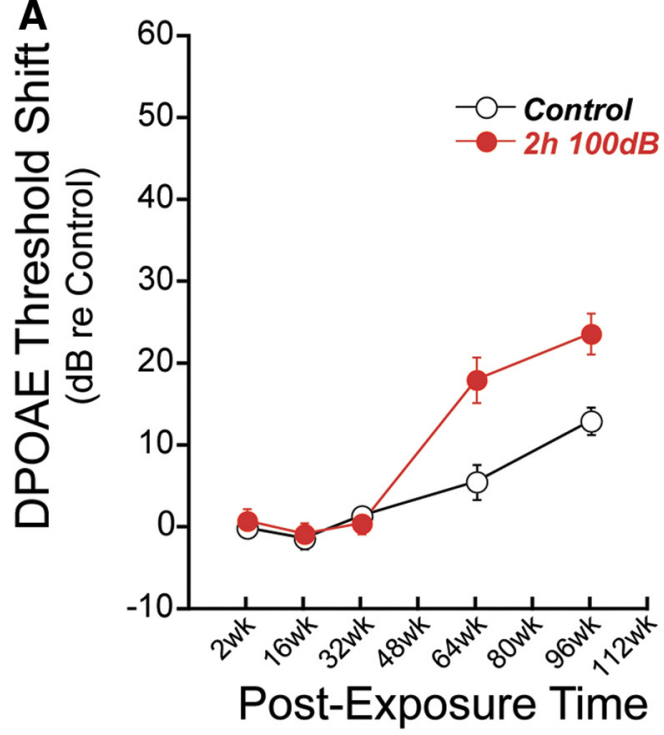

B

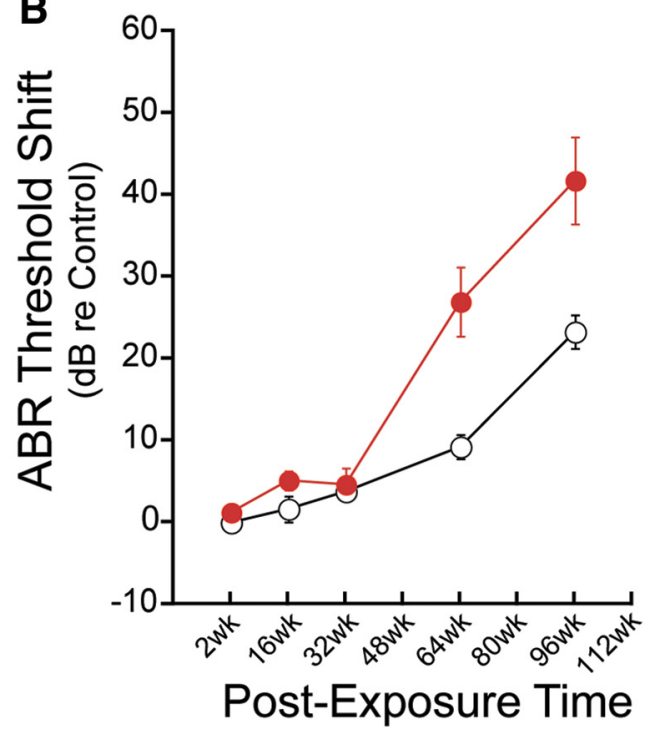

Figure 9. Synaptopathic noise exposure exaggerates threshold shifts in aging ears. After 1 synaptopathic ( $100 \mathrm{~dB}, 2 \mathrm{~h})$ exposure at $16 \mathrm{weeks}$, thresholds return to baseline by 2 weeks after exposure (Fig. $1 A, B)$, but exposed mice show larger subsequent threshold shifts than controls as they age after noise. Shown here for $32 \mathrm{kHz}$, shifts for both DPOAE $(\boldsymbol{A})$ and $A B R(B)$ diverged at 64 weeks after exposure and were greater in the ABR. Data are means $\pm \mathrm{SE}$; group sizes are provided in Figure 3 legend. All shifts are calculated relative to thresholds in 16 week unexposed mice. Key in $\boldsymbol{A}$ applies to both panels.
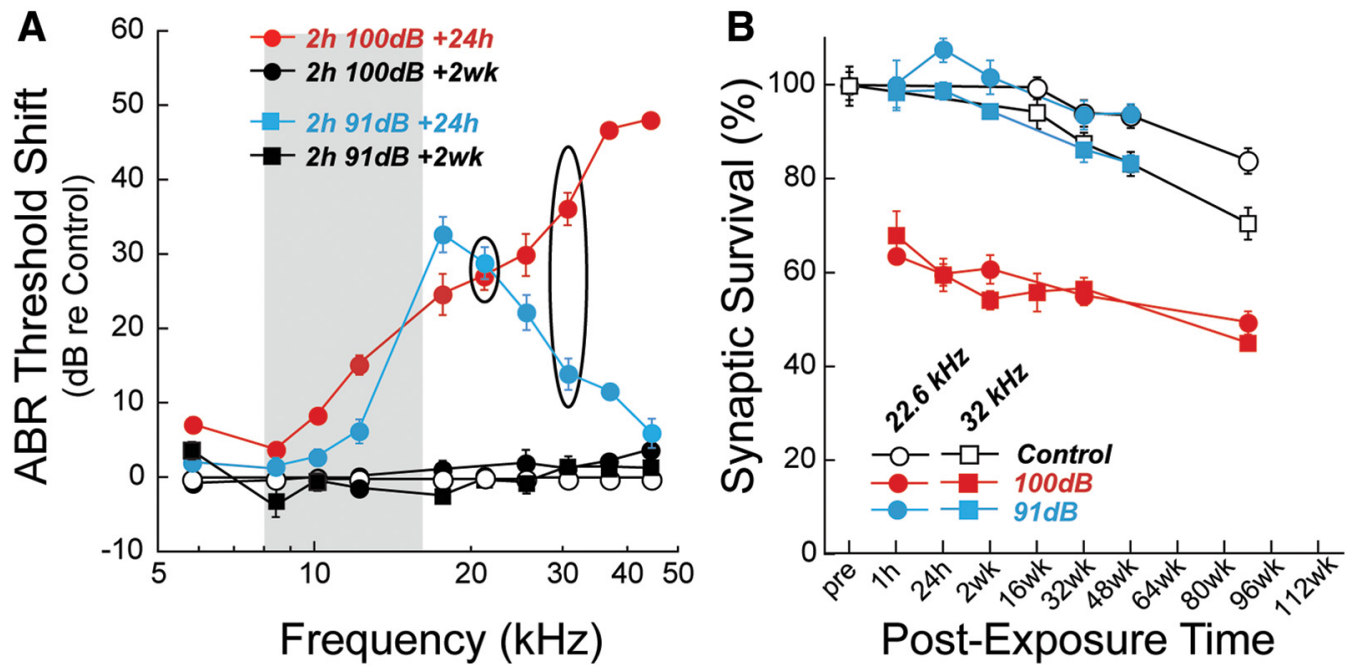

Figure 10. TTS magnitude does not predict synaptopathy. Both the $91 \mathrm{~dB}$ and the $100 \mathrm{~dB}$ exposures produced large transient threshold elevations $(\boldsymbol{A})$, although shifts from the latter were larger and spread farther toward the cochlear base. Synapse loss in the $32 \mathrm{kHz}$ region was seen for 100 , not $91 \mathrm{~dB}$ exposure $(\boldsymbol{B})$. At $22.6 \mathrm{kHz}$, the acute threshold shifts are identical from the two exposures $(\boldsymbol{A})$; however, the higher level exposure produced large synapse loss while the lower level exposure produced none (B). Data are means \pm SE; group sizes are provided in Figure 1 legend.

risk, and thus to establish permissible exposure levels for occupational exposure (Occupational Safety and Health Organization, 1981). The Occupational Safety and Health Organization (OSHA) uses a criterion of $90 \mathrm{~dB}$ for $8 \mathrm{~h}$, and a $5 \mathrm{~dB}$ decrement/increment for every doubling/halving of exposure duration. Therefore, 95 $\mathrm{dB}$ exposure is allowed for $4 \mathrm{~h}, 100 \mathrm{~dB}$ exposure for $2 \mathrm{~h}$, and so on. With a criterion level of $85 \mathrm{~dB}$ and an exchange rate of $3 \mathrm{~dB}$, National Institute for Occupational Safety and Health (NIOSH) guidelines are more conservative (NIOSH, 1998). Our $100 \mathrm{~dB}, 2 \mathrm{~h}$ exposure meets the OSHA standard and our $91 \mathrm{~dB}, 2 \mathrm{~h}$ exposure meets the NIOSH standard. The $91 \mathrm{~dB}, 8 \mathrm{~h}$ exposure approximates the time-intensity trade for 100 versus $90 \mathrm{~dB}$ exposure (OSHA). Although none of the exposures produced permanent threshold shift, the $100 \mathrm{~dB}, 2 \mathrm{~h}$ and $91 \mathrm{~dB}, 8 \mathrm{~h}$ exposures were clearly damaging to the ear. For both OSHA and NIOSH, expo- sure limits (dBA) assume an $8 \mathrm{~h}$ work day $5 \mathrm{~d}$ /wk over a working lifetime; therefore, our findings cannot be compared directly. Nevertheless, they provide a framework from which to begin reconsideration of noise risk.

Vulnerability of neuronal subgroups

In our models of primary cochlear neurodegeneration, loss of IHC synapses and type I afferent neurons are proportional and subtotal, reaching no more than $\sim 50 \%$ until hair cell loss commences. This subtotal loss may reflect a differential vulnerability among afferent fiber subtypes. Mammalian auditory nerve fibers can be grouped by spontaneous rates (SRs) of firing. Fibers with high thresholds ( $\sim 40 \%$ of the population) have low SRs and fibers with low thresholds $(\sim 60 \%)$ have high SRs (Liberman, 1978; Tsuji et al., 1997). Low-SR neurons preferentially disappear 
from the fiber samples in acoustically traumatized cats (Liberman and Kiang, 1978) and guinea pigs (Furman et al., 2013) and in aged gerbils (Schmiedt et al., 1996). Low- and high-SR fibers arise from peripheral terminals on opposite sides of the IHC (Liberman, 1982) and immunostaining for glutamate transporters, which take up synaptic glutamate, is less intense on the modiolar side of the IHC, where low-SR synapses predominate (Furness and Lawton, 2003). Furthermore, low-SR fiber terminals have fewer mitochondria (Liberman, 1980) and thus may be less able to buffer the $\mathrm{Ca}^{2+}$ overload that is important in the genesis of glutamate excitotoxicity (Szydlowska et al., 2010).

The remaining $5 \%$ of auditory nerve fibers, the type II fibers contacting OHCs, do not show the acute terminal swelling seen in type I terminals after overstimulation or perfusion of glutamate agonists (Robertson, 1983; Pujol et al., 1993). The relative invulnerability of the type II terminals likely arises because they do not express the same AMPA-type glutamate receptors (e.g., GluA2) as type I terminals (Matsubara et al., 1996; Liberman et al., 2011).

\section{Noise-age interactions and application to humans}

Declines in hearing function with age are multifactorial and there is general agreement that noise exposure is a common contributor. It is estimated that 10 million people in the United States have "hearing loss"; that is, permanent threshold elevation, related to their noise exposure (NIOSH, 2013). Permanent noise-induced threshold shifts combine with age-related shifts (Kujawa and Liberman, 2006) in ways that remain unclear, but whatever the combination, their presence can interfere with communication and compromise quality of life.

In addition to the high prevalence of permanent noiseinduced threshold shifts, it is likely that exposure to TTSproducing noise affects a dramatically larger proportion of the population. Although traditionally not considered of lasting significance due to recovered thresholds, the work presented here shows that such exposures can have permanent and progressive consequences for aging ears and hearing.

Attempts to characterize such a noise-age relationships in the human have focused on audiometric thresholds and have failed to yield consensus opinions (Gates et al., 2000; Rosenhall, 2003; Lee et al., 2005; Cruickshanks et al., 2010). Here, using genetically identical animals receiving highly stereotyped exposures with all other variables held constant between exposed and unexposed age-matched cohorts, late exacerbations in threshold shifts were seen as animals aged after noise. Although OHCs are not lost acutely from the exposures studied here, exaggeration of agerelated DPOAE threshold shifts and OHC losses after synaptopathic noise, particularly at high frequencies, suggest progressive involvement of cochlear amplifier function. It is possible that noise exposure also leads to early onset of sublethal changes in the expression levels of key proteins such as prestin (Xia et al., 2013).

Beyond these hair cell losses and corresponding threshold elevations, we present clear evidence that prior noise dramatically exacerbates synaptic and neural losses that otherwise occur with aging. These changes begin much earlier in time and progress as animals age after noise to involve cochlear regions that initially appeared unaffected by the exposure. The data suggest that, for such interactions to occur between noise and aging, a key requirement is the acute production of some degree of exposure-induced synaptopathy, perhaps in the cochlear base.

The fact that apparently reversible noise damage can have dramatic long-term consequences in amplifying age-related sensorineural hearing loss is of significance in the consideration of noise-risk assessment for human populations. Such findings also are intriguing in light of human temporal bone studies showing steady loss of cochlear neuronal populations with age, even in the absence of hair cell loss (Makary et al., 2011); additional study will be required to determine whether this loss is preceded by synapse loss and if it is accelerated by noise exposure, as has been demonstrated here. Humans show increasing difficulties discriminating speech in noisy environments through middle and old age, even when audibility remains normal (Snell and Frisina, 2000; Grose et al., 2006). Beyond any loss of audibility, accelerated and exaggerated loss of synaptic connections between IHCs and cochlear nerve fibers likely contributes to problems hearing in noise (Bharadwaj et al., 2014) and to central changes associated with persistent tinnitus (Knipper et al., 2013), both common in noise-exposed and aging groups.

Together, the present results demonstrate that a single synaptopathic exposure has effects on the aging ear that continue long after the noise has stopped. Further, whereas therapeutic efforts that aim to protect hair cells and thresholds from age-related and noise-induced declines are important, they appear to target events occurring rather late in the degenerative processes that we have characterized.

\section{References}

ACOEM Task Force on Occupational Hearing Loss, Kirchner DB, Evenson E, Dobie RA, Rabinowitz P, Crawford J, Kopke R, Hudson TW (2012) Occupational noise-induced hearing loss: ACOEM Task Force on Occupational Hearing Loss. J Occup Environ Med 54:106-108. CrossRef Medline

Bharadwaj HM, Verhulst S, Shaheen L, Liberman MC, Shinn-Cunningham BG (2014) Cochlear neuropathy and the coding of supra-threshold sound. Front Syst Neurosci 8:26. Medline

Bohne BA, Harding GW (2000) Degeneration in the cochlea after noise damage: primary versus secondary events. Am J Otol 21:505-509. Medline

Bourien J, Tang Y, Batrel C, Huet A, Lenoir M, Ladrech S, Desmadryl G, Nouvian R, Puel JL, Wang J (2014) Contribution of auditory nerve fibers to compound action potential of the auditory nerve. J Neurophysiol 112:1025-1039. CrossRef Medline

Canlon B, Meltser I, Johnsson P, Tahera Y (2007) Glucocorticoid receptors modulate auditory sensitivity to acoustic trauma. Hear Res 226(1-2):61-69.

Chen Z, Kujawa SG, Sewell WF (2007) Auditory sensitivity regulation via rapid changes in expression of surface AMPA receptors. Nat Neurosci 10:1238-1240. CrossRef Medline

Chen Z, Peppi M, Kujawa SG, Sewell WF (2009) Regulated expression of surface AMPA receptors reduces excitotoxicity in auditory neurons. J Neurophysiol 102:1152-1159. CrossRef Medline

Cruickshanks KJ, Nondahl DM, Tweed TS, Wiley TL, Klein BE, Klein R, Chappell R, Dalton DS, Nash SD (2010) Education, occupation, noise exposure history and the 10-yr cumulative incidence of hearing impairment in older adults. Hear Res 264(1-2):3-9.

Furman AC, Kujawa SG, Liberman MC (2013) Noise-induced cochlear neuropathy is selective for fibers with low spontaneous rates. J Neurophysiol 110:577-586. CrossRef Medline

Furness DN, Lawton DM (2003) Comparative distribution of glutamate transporters and receptors in relation to afferent innervation density in the mammalian cochlea. J Neurosci 23:11296-11304. Medline

Gates GA, Schmid P, Kujawa SG, Nam B, D’Agostino R (2000) Longitudinal threshold changes in people with audiometric notches. Hear Res 141: 220-228. CrossRef Medline

Grant L, Yi E, Glowatzki E (2010) Two modes of release shape the postsynaptic response at the inner hair cell ribbon synapse. J Neurosci 30:42104220. CrossRef Medline

Grose JH, Hall JW 3rd, Buss E (2006) Temporal processing deficits in the pre-senescent auditory system. J Acoust Soc Am 119:2305-2315. CrossRef Medline

Institute of Medicine (2005) Noise and military service: implications for hearing loss and tinnitus (Humes L, Joellenbeck L, Durch J, eds). Washington, DC: National Academies.

Khimich D, Nouvian R, Pujol R, Tom Dieck S, Egner A, Gundelfinger ED, 
Moser T (2005) Hair cell synaptic ribbons are essential for synchronous auditory signalling. Nature 434:889-894. CrossRef Medline

Knipper M, Van Dijk P, Nunes I, Rüttiger L, Zimmermann U (2013) Advances in the neurobiology of hearing disorders: recent developments regarding the basis of tinnitus and hyperacusis. Prog Neurobiol 111:17-33. CrossRef Medline

Kujawa SG, Liberman MC (2006) Acceleration of age-related hearing loss by early noise exposure: evidence of a misspent youth. J Neurosci 26: 2115-2123. CrossRef Medline

Kujawa SG, Liberman MC (2009) Adding insult to injury: cochlear nerve degeneration after "temporary" noise-induced hearing loss. J Neurosci 29:14077-14085. CrossRef Medline

Lee FS, Matthews LJ, Dubno JR, Mills JH (2005) Longitudinal study of puretone thresholds in older persons. Ear Hear 26:1-11. Medline

Liberman LD, Wang H, Liberman MC (2011) Opposing gradients of ribbon size and AMPA receptor expression underlie sensitivity differences among cochlear-nerve/hair-cell synapses. J Neurosci 31:801-808. CrossRef Medline

Liberman MC (1978) Auditory-nerve response from cats raised in a lownoise chamber. J Acoust Soc Am 63:442-455. CrossRef Medline

Liberman MC (1980) Morphological differences among radial afferent fibers in the cat cochlea: an electron-microscopic study of serial sections. Hear Res 3:45-63. CrossRef Medline

Liberman MC (1982) Single-neuron labeling in the cat auditory nerve. Science 216:1239-1241. CrossRef Medline

Liberman MC, Kiang NY (1978) Acoustic trauma in cats: cochlear pathology and auditory-nerve activity. Acta Otolaryngol Suppl 358:1-63. Medline

Liberman MC, Dodds LW, Pierce S (1990) Afferent and efferent innervation of the cat cochlea: quantitative analysis with light and electron microscopy. J Comp Neurol 301:443-460. CrossRef Medline

Liberman MC, Chesney CP, Kujawa SG (1997) Effects of selective inner hair cell loss on DPOAEs in carboplatin-treated chinchillas. Auditory Neuroscience 3:255-268.

Lin HW, Furman AC, Kujawa SG, Liberman MC (2011) Primary neural degeneration in the guinea pig cochlea after reversible noise-induced threshold shift. J Assoc Res Otolaryngol 12:605-616. CrossRef Medline

Lobarinas E, Salvi R, Ding D (2013) Insensitivity of the audiogram to carboplatin induced inner hair cell loss in chinchillas. Hear Res 302:113-120. CrossRef Medline

Makary CA, Shin J, Kujawa SG, Liberman MC, Merchant SN (2011) Agerelated primary cochlear neuronal degeneration in human temporal bones. J Assoc Res Otolaryngol 12:711-717. CrossRef Medline

Matsubara A, Laake JH, Davanger S, Usami S, Ottersen OP (1996) Organization of AMPA receptor subunits at a glutamate synapse: a quantitative immunogold analysis of hair cell synapses in the rat organ of Corti. J Neurosci 16:4457-4467. Medline

Meyer AC, Frank T, Khimich D, Hoch G, Riedel D, Chapochnikov NM, Yarin YM, Harke B, Hell SW, Egner A, Moser T (2009) Tuning of synapse number, structure and function in the cochlea. Nat Neurosci 12:444-453. CrossRef Medline

Müller M, von Hünerbein K, Hoidis S, Smolders JW (2005) A physiological place-frequency map of the cochlea in the CBA/J mouse. Hear Res 202: 63-73. CrossRef Medline

National Institute for Occupational Safety and Health (1998) Criteria for a recommended standard: occupational noise exposure, revised criteria 1998. U.S. Department of Health and Human Services, Centers for Disease Control and Prevention, National Institute for Occupational Safety and Health Publication No. 98-126. Cincinnati: NIOSH.

National Institute for Occupational Safety and Health (2013) Noise and hearing loss prevention. Available from: http://www.cdc.gov/niosh/ topics/noise/stats.html. Accessed Oct. 28, 2014.
Occupational Safety and Health Association (1981) Occupational noise exposure: hearing conservation amendment. U.S. Department of Labor, Occupational Safety and Health Administration Publication 46 Fed. Reg. 4078-4179. Washington, DC: U.S. Department of Labor.

Peppi M, Kujawa SG, Sewell WF (2011) A corticosteroid-responsive transcription factor, promyelocytic leukemia zinc finger protein, mediates protection of the cochlea from acoustic trauma. J Neurosci 31:735-741. CrossRef Medline

Plack CJ, Barker D, Prendergast G (2014) Perceptual consequences of "hidden" hearing loss. Trends Hear 18:pii:2331216514550621. CrossRef Medline

Pujol R, Puel JL, Gervais d'Aldin C, Eybalin M (1993) Pathophysiology of the glutamatergic synapses in the cochlea. Acta Otolaryngol 113:330-334. Medline

Rabinowitz PM (2012) The public health significance of noise-induced hearing loss. In: Noise-induced hearing loss: scientific advances (Le Prell CG, Henderson D, Fay RR, Popper AN, eds), pp 13-25. New York: Springer.

Robertson D (1983) Functional significance of dendritic swelling after loud sounds in the guinea pig cochlea. Hear Res 9:263-278. CrossRef Medline

Robertson D, Johnstone BM (1980) Acoustic trauma in the guinea pig cochlea: early changes in ultrastructure and neural threshold. Hear Res 3:167-179. CrossRef Medline

Rosenhall U (2003) The influence of ageing on noise-induced hearing loss. Noise Health 5:47-53. Medline

Ruel J, Wang J, Rebillard G, Eybalin M, Lloyd R, Pujol R, Puel JL (2007) Physiology, pharmacology and plasticity at the inner hair cell synaptic complex. Hear Res 227:19-27. CrossRef Medline

Saunders JC, Cohen YE, Szymko YM (1991) The structural and functional consequences of acoustic injury in the cochlea and peripheral auditory system: A five year update. J Acoust Soc Am 90:136-146. CrossRef Medline

Schaette R, McAlpine D (2011) Tinnitus with a normal audiogram: physiological evidence for hidden hearing loss and computational model. J Neurosci 31:13452-13457. CrossRef Medline

Schmiedt RA, Mills JH, Boettcher FA (1996) Age-related loss of activity of auditory-nerve fibers. J Neurophysiol 76:2799-2803. Medline

Schuknecht HF, Woellner RC (1955) An experimental and clinical study of deafness from lesions of the cochlear nerve. J Laryngol Otol 69:75-97. CrossRef Medline

Sergeyenko Y, Lall K, Liberman MC, Kujawa SG (2013) Age-related cochlear synaptopathy: an early-onset contributor to auditory functional decline. J Neurosci 33:13686-13694. CrossRef Medline

Snell KB, Frisina DR (2000) Relationships among age-related differences in gap detection and word recognition. J Acoust Soc Am 107:1615-1626. CrossRef Medline

Spoendlin H (1972) Innervation densities of the cochlea. Acta Otolaryngol 73:235-248. CrossRef Medline

Spongr VP, Flood DG, Frisina RD, Salvi RJ (1997) Quantitative measures of hair cell loss in CBA and C57BL/6 mice throughout their lifespans. J Acoust Soc Am 101:3546-3553. CrossRef Medline

Szydlowska K, Tymianski M (2010) Calcium, ischemia and excitotoxicity. Cell Calcium 47:122-129. CrossRef Medline

Tsuji J, Liberman MC (1997) Intracellular labeling of auditory nerve fibers in guinea pig: Central and peripheral projections. J Comp Neurol 381: 188-202. Medline

Xia A, Song Y, Wang R, Gao SS, Clifton W, Raphael P, Chao SI, Pereira FA, Groves AK, Oghalai JS (2013) Prestin regulation and function in residual outer hair cells after noise-induced hearing loss. PLoS One 8:e82602. CrossRef Medline 